\title{
Perceptions of Doppler ultrasound for rheumatoid arthritis disease activity assessment and education
}

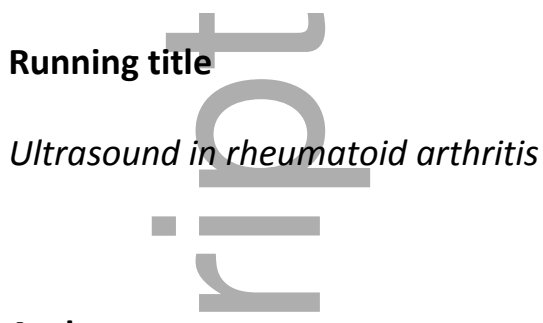

\section{Authors}

Fredrick Joshua, Christine Bailey, Mona Marabani, Evange Romas, Raymond White, Peter Wong

\section{Author affiliations}

Fredrick Joshua

Combined Rheumatology Practice and Macquarie University, Sydney, NSW, Australia

Christine Bailey

AbbVie Australia, Sydney, NSW, Australia

Mona Marabani

Private Rheumatology Practice, Campsie, NSW, Australia

Evange Romas

Department of Medicine, University of Melbourne, Melbourne, VIC, Australia

Raymond White

Private Rheumatology Practice, Campbelltown, NSW, Australia

Peter Wong

Mid-North Coast Arthritis Clinic and UNSW Rural Clinical School, Coffs Harbour, NSW, Australia

\section{Author contributions}

This is the author manuscript accepted for publication and has undergone full peer review but has not been through the copyediting, typesetting, pagination and proofreading process, which may lead to differences between this version and the Version of Record. Please cite this article as doi: 10.1111/1756-185X.13034

This article is protected by copyright. All rights reserved 
- Study concept and design: Fredrick Joshua, Mona Marabani, Evange Romas, Raymond White, Peter Wong

- Acquisition of data: Christine Bailey, Evange Romas, Raymond White, Peter Wong

- Analysis and interpretation of data: Fredrick Joshua, Christine Bailey, Mona Marabani, Evange Romas, Raymond White, Peter Wong

- Initial drafting of the manuscript: Fredrick Joshua, with assistance from Hazel Palmer and Adrianna Kalous of Scriptix Pty Ltd

- Critical revision of the manuscript for important intellectual content: Fredrick Joshua, Christine Bailey, Mona Marabani, Evange Romas, Raymond White, Peter Wong

\section{Corresponding author}

A/Professor Fredrick Joshua

Suite G3, 64 Talavera Rd

Macquarie Park NSW 2113

Telephone: +61 (02) 98889798

Email: fredjoshua@unsw.edu.au

\section{Acknowledgements}

AbbVie contributed to the design, implementation, intellectual content and funding of the DEDUCE Medical Practice Activity. This study was funded by AbbVie Australia. The sponsor reviewed the final manuscript before submission. Statistical analyses were performed by Annie Solterbeck from Statistical Revelations and funded by AbbVie Australia. The authors acknowledge that editorial assistance in preparing the manuscript was provided by Adrianna Kalous, PhD, and Hazel Palmer, CMPP, of Scriptix Pty Ltd; this contribution was funded by AbbVie Australia. Fredrick Joshua has served as a consultant for AbbVie, Schering-Plough, Servier, Pfizer, MSD, Roche, Janssen, Sanofi, UCB, and BMS. Christine Bailey is an employee (Medical Scientific Liaison) of Abbvie Australia. Mona Marabani has served as a consultant for AbbVie, BMS, and Novartis and as an investigator in clinical trials for AbbVie, Roche and Daiichi-Sankyo; and has received conference or travel support from Pfizer, BMS, Roche and UCB. Evange Romas has served as a consultant for AbbVie, UCB, and Amgen; has received research funding from AbbVie, UCB, Servier, and Amgen; and has received speaker fees from AbbVie and Amgen. Raymond White has received an honorarium from AbbVie and has received conference support from AbbVie, BMS, Janssen, Roche, and UCB. Peter Wong has served as an

This article is protected by copyright. All rights reserved 
investigator in clinical trials for Abbott, Celgene, Roche, Daiichi-Sankyo and UCB; has received conference or travel support from AbbVie, Servier, Roche, BMS and Pfizer; has received speaking and education honoraria from Amgen, Novartis, and Servier; has received nurse support funding from AbbVie, Actelion, and Roche; and has received research grants from BMS and Pfizer.

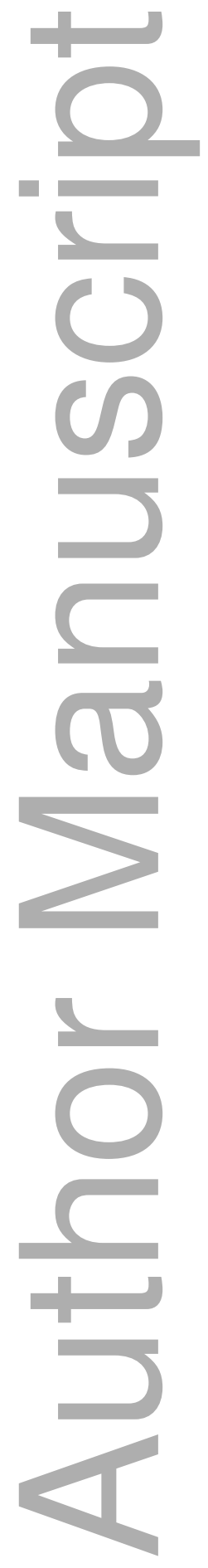

This article is protected by copyright. All rights reserved 
Received Date : 25-May-2016

Revised Date : 22-Aug-2016

-

Accepted Date: 07-Nov-2016

Article type : Original Article

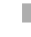

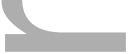

C

ABSTRACT

Aim: The aim of this qualitative study was to report the findings of the DEfining rheumatoid arthritis progression using Doppler Ultrasound in Clinical practicE (DEDUCE) Medical Practice Activity, which was developed to facilitate the utilization of Doppler ultrasound (DUS) by Australian rheumatologists in the treatment of patients with rheumatoid arthritis (RA).

Method: Twenty-one rheumatologists recruited a total of 80 patients with RA in Disease Activity Score 28 (DAS28) remission for DUS assessment and completed a pre- and post-activity questionnaire assessing their experience with DUS, as well as a 6-month follow-up questionnaire. Rheumatologists discussed DUS results with patients using visual aids. Patients completed a pre- and post-DUS assessment questionnaire. Data were summarized using descriptive statistics.

Results: Following completion of the activity, $95 \%$ of rheumatologists (20/21) believed DUS was a useful assessment tool for patients with RA. The majority found the DUS results useful and more than half thought the DUS assessment fit well into their consultation. A majority of rheumatologists indicated they would use DUS imaging in patients with low disease activity and remission, and for disease activity assessment to inform in therapeutic decision-making. All patients who responded found the visual aids useful and most felt that discussing DUS results improved understanding of their disease and would help with medication adherence.

Conclusion: Incorporation of DUS imaging into routine clinical practice is feasible, encourages rheumatologists to utilize and expand their clinical application of DUS imaging in patients with RA, and may improve patient understanding of their disease and adherence to medication.

This article is protected by copyright. All rights reserved 
Keywords: rheumatoid arthritis; remission; Doppler ultrasound; imaging; patient education; attitudes.

\section{INTRODUCTION}

Doppler ultrasound (DUS) can detect active synovitis and predict joint destruction, flare, and short-term relapse in patients with rheumatoid arthritis (RA) who meet clinical remission criteria. ${ }^{1-5}$ As synovitis often results in joint damage, ${ }^{6}$ subclinical synovitis may lead to disease flare and may help explain the progressive joint damage that is observed even in patients who appear to be in clinical remission. ${ }^{7-10}$ DUS may therefore be an important tool to improve assessment of disease activity and aid in disease management decisions. ${ }^{2,11,12}$

Doppler ultrasound is a non-radioactive, portable, relatively inexpensive imaging technique that is acceptable to patients and allows real-time imaging in multiple planes. ${ }^{13}$ Despite these advantages and growing interest in its use, musculoskeletal ultrasonography is frequently under-utilized by rheumatologists, ${ }^{14-18}$ with lack of training among the most commonly cited reasons. ${ }^{19-21}$

Doppler ultrasound may also be useful as a patient education tool to improve both patient understanding of their disease and medication adherence. Showing patients with RA real-time DUS images of their inflamed joints on one occasion increased their belief in the necessity of medication (versus concern about taking medication). ${ }^{22}$ The visual nature of DUS may be important in patient education, as real-time demonstration of joint structures and damage and the ability to highlight critical features for patients using their own anatomy may improve understanding and help patients recognize the need for medication. ${ }^{23}$

The purpose of this study was to report the findings of the DEfining rheumatoid arthritis progression using Doppler Ultrasound in Clinical practicE (DEDUCE) Medical Practice Activity. This study was developed to facilitate the utilization of DUS by Australian rheumatologists as part of routine assessment and ongoing evaluation of therapy in patients with RA. The objectives of the present study were to assess: 1 ) the current use of DUS by Australian rheumatologists, 2) the feasibility of incorporating a single DUS assessment into routine clinical practice to measure RA disease activity in patients who are considered to be in remission as measured using the Disease Activity Score 28 (DAS28), 3) whether exposure to 
DUS altered rheumatologists' attitudes and clinical practice, and 4) whether DUS assessment improved patient understanding of their RA and medication adherence.

\section{METHODOLOGY}

\section{Participants}

The DEDUCE Medical Practice Activity was open to all Australian rheumatologists who use DUS directly themselves, have access to DUS in-practice, or can access DUS from external ultrasonography practices. Each participating rheumatologist recruited 4 to 6 patients for DUS assessment. To be included in the study, patients had to meet the following inclusion criteria: aged $\geq 18$ years; having a diagnosis of RA and seeing a rheumatologist every 3 months; currently classified as being in DAS28 remission (DAS28 score <2.6). There were no criteria regarding which joints were involved.

The study was approved by the Bellberry Human Research Ethics Committee (Eastwood, South Australia) and was performed in accordance with the Declaration of Helsinki. All patients included in the study provided written informed consent to the collection and use of anonymous survey data to support future publications.

\section{Study design}

Prior to enrolling patients, participating rheumatologists completed a pre-activity questionnaire assessing their DUS experience. Eligible and consenting patients completed a pre-assessment survey to assess their current knowledge before the consultation with their rheumatologist. Rheumatologists then incorporated a DUS assessment into the consultation, either within the practice or by referral to an external ultrasonography practice. The joints evaluated were determined by the rheumatologist based on the patient's joint involvement and were therefore different for each patient. Rheumatologists discussed the patient's DUS imaging results with them in conjunction with specifically developed visual aids to help with patient interaction. The visual aids consisted of DUS photograph examples showing various levels of synovitis (Figure 1). After DUS assessment, patients completed a post-assessment questionnaire. Rheumatologists completed a post-activity questionnaire after all enrolled patients had been assessed, as well as a 6-month follow-up survey, each assessing experience and attitudes toward the use of DUS imaging. 
All patient data were de-identified by assigning a unique identification number to each enrolled patient. Anonymous patient data were stored and analyzed in line with ethical requirements.

\section{Statistical analyses}

All data from rheumatologist and patient questionnaires were analyzed using descriptive statistics.

\section{RESULTS}

\section{Characteristics of enrolled rheumatologists and participating patients}

Characteristics of the 21 rheumatologists who participated in DEDUCE are summarized in Table 1. Approximately $70 \%$ of rheumatologists had experience with the use of DUS imaging for the assessment of RA activity, either through performing it themselves within the practice or by referring patients to an external ultrasonography practice. Characteristics of the 80 patients who completed the pre-assessment survey are summarized in Table 2.

\section{Current DUS use}

Among the 15 rheumatologists who had experience with the use of DUS imaging, the most common application was as a diagnostic tool to confirm the diagnosis of early RA, followed by assessment of disease activity to inform therapeutic decisions (Table 3). DUS imaging was mainly used to measure disease activity in patients with low disease activity (Table 3 ). All 15 rheumatologists routinely discussed DUS imaging results with their patients. Most rheumatologists already believed that utilizing DUS to assess RA in patients aided in therapeutic decision-making and communication with patients (Table 3). Fewer believed that the use of DUS aided in patient adherence with therapy.

The most common reasons for not using DUS by rheumatologists were inconvenience to patients $(4 / 6 ; 66.7 \%)$, expense to patients $(3 / 6 ; 50 \%)$, concerns about the utility of DUS reports $(3 / 6 ; 50 \%)$, lack of benefit/unnecessary $(2 / 6 ; 33.3 \%)$, and other reasons $(1 / 6 ; 16.7 \%)$. 


\section{Utility of DUS assessment in routine clinical practice}

Most rheumatologists found the results of DUS imaging useful; 9 of 21 rheumatologists (42.9\%) found the results very useful, 7 rheumatologists (33.3\%) found the results somewhat useful, and 5 rheumatologists (23.8\%) were undecided. More than half of the rheumatologists found that DUS assessment integrated into their usual consultation very well $(4 / 21 ; 19 \%)$ or quite well $(8 / 21 ; 38.1 \%)$. Only 4 rheumatologists $(19 \%)$ found that it did not fit well, $4(19 \%)$ were undecided, and 1 did not provide a response. Most rheumatologists (19/21; 90.5\%) discussed the DUS imaging results with their patients. Of these rheumatologists, most found the patient visual aids useful (8/19 [42.1\%] found them very useful, $8 / 19$ [42.1\%] found them somewhat useful, and 3/19 [15.8\%] were undecided).

Sixty-six patients completed the post-assessment survey. Of these patients, 61 indicated that their rheumatologist used the visual aids to explain the use of DUS. All patients who responded found the visual aids useful to some extent (very useful, 27 [44.3\%]; useful, 23 [37.7\%]; somewhat useful, 3 [4.9\%]; a little useful, 3 [4.9\%]).

\section{Impact of DUS assessment on clinical practice and clinician attitudes}

Six months following completion of the DEDUCE study, all except 1 rheumatologist considered DUS useful for the assessment of patients with RA (very useful, 14/21 [66.7\%]; somewhat useful, 6/21 [28.6\%]; undecided, 1/21 [4.8\%]). Nineteen of 21 rheumatologists (90.5\%) had incorporated DUS into their usual consultation routine; 11 rheumatologists (52.4\%) had referred more than 10 patients to DUS, 8 (38.1\%) had referred 1 to 10 patients, and $2(9.5 \%)$ had not referred any patients. Most rheumatologists were either trained in DUS imaging $(14 / 21 ; 66.7 \%)$ or intended to pursue training $(4 / 21 ; 19.0 \%)$. The most common way rheumatologists planned to implement DUS imaging into clinical practice was by performing it themselves (18/21; $85.7 \%)$, followed by referring patients externally $(2 / 21 ; 9.5 \%)$ and utilizing a trained dedicated rheumatologist $(1 / 21 ; 4.8 \%)$. In a separate question, however, 1 rheumatologist (4.8\%) said that he would not continue to use DUS imaging for the assessment of RA.

At the time of enrollment, no rheumatologists used DUS imaging to facilitate patient discussion and only one third of rheumatologists used DUS imaging for the assessment of disease activity to inform in therapeutic decision-making; 6 months after completing DEDUCE, 
$66.7 \%$ and $95.2 \%$ of rheumatologists, respectively, believed these were appropriate applications of DUS imaging (Table 3).

The proportion of rheumatologists who believed that utilizing DUS to assess patients with RA aided therapeutic decision-making and patient communication was unchanged (Table 3). Few rheumatologists believed inconvenience, expense, concerns about DUS utility, lack of benefit/unnecessary, or other were reasons not to use DUS (3/21 [14.3\%], 1/21 [4.8\%], 1/21 [4.8\%], 2/21 [9.5\%], and 1/21 [4.8\%], respectively).

\section{Impact of DUS assessment on patient attitudes}

Most patients who completed the post-assessment questionnaire agreed that DUS imaging was a useful tool in assessing disease activity in RA (strongly agree, 37/66 [56.1\%]; agree, 19/66 [28.8\%]; undecided, 8/66 [12.1\%]; no response, 2/66 [3.0\%]). Of the 58 patients (87.9\%) who said their rheumatologist discussed the DUS imaging results with them, most agreed or strongly agreed that this improved understanding of their disease (strongly agree, 32/58 [55.2\%]; agree, 19/58 [32.8\%]; undecided, 7/58 [12.1\%]) and would improve their adherence with medications (strongly agree, 27/58 [46.6\%]; agree, 28/58 [48.3\%]; undecided, $3 / 58[5.2 \%])$.

\section{DISCUSSION}

This small qualitative report of the findings of the DEDUCE Medical Practice Activity suggests that the incorporation of DUS assessment into routine clinical practice to measure RA disease activity is useful and feasible. The Medical Practice Activity promoted rheumatologist uptake of DUS, with the majority of rheumatologists having incorporated DUS into their usual consultation routine within 6 months. Most rheumatologists planned to implement DUS by performing it themselves. Rheumatologists commonly state that lack of training is a barrier to the uptake of musculoskeletal US in routine clinical practice. ${ }^{19-21}$ This study suggests that exposure to DUS encourages rheumatologists to implement DUS into their practice.

The use of DUS helps inform in therapeutic decision-making. ${ }^{12,24}$ The most striking change in rheumatologists' attitudes toward DUS after completing the Medical Practice Activity was an increase in the belief that DUS imaging is appropriate for disease activity assessment to inform in therapeutic decision-making. Exposure to DUS through the Medical 
Practice Activity also appeared to alleviate rheumatologists' concerns about the utilization of DUS, particularly the potential inconvenience and expense to patients and concerns about the utility of DUS reports.

There is increasing evidence that power DUS detects low but clinically significant levels of RA disease activity in patients who appear to be in clinical remission. It has even been proposed that DUS imaging should be a component of remission criteria. ${ }^{2,11,12} \mathrm{An}$ international study (TURA, NCT02056184) designed to determine whether targeted DUS improves RA outcomes in patients in disease remission is currently being conducted.

The use of DUS imaging for disease activity assessment in patients in remission was uncommon among the rheumatologists enrolled in the Medical Practice Activity. However, almost $60 \%$ of rheumatologists regarded this as an appropriate application of DUS after completing the activity. Thus, exposure to DUS appeared to improve rheumatologists' knowledge of appropriate applications for DUS imaging. It should be noted, however, that participants were not randomly recruited and therefore the results may be affected by selection bias.

Medication adherence in patients with RA is suboptimal, varying from 30 to $80 \%{ }^{25}$ This is a complex issue and is impacted by patient knowledge and beliefs about their disease. 25,26 There are few published data regarding the effect of musculoskeletal US on patient understanding and adherence to medication. ${ }^{22}$ This study suggests discussing DUS imaging results with patients may facilitate patient understanding and adherence to medication. However, this was a small qualitative study with no objective measure of patient understanding and medication adherence. It is also possible that there may have been a selection bias for patients with positive attitudes towards DUS imaging to complete the postassessment questionnaire, which may have resulted in an overestimation of the positive impact of discussing DUS imaging results. Nevertheless, our findings should encourage further research regarding the utility of DUS as a patient educational tool.

The educational potential of DUS assessment may be limited when imaging is performed externally, as the treating rheumatologist is not present to contemporaneously explain to patients the significance of observed changes. Therefore, rheumatologists were asked to use specific visual aids to help explain DUS imaging to patients. Most rheumatologists, and all patients who responded, felt the visual aids were useful. Although there was no control group to enable evaluation of the impact of the visuals aids on patient attitudes towards 
understanding of disease and medication adherence, these findings warrant future investigation of the use of visual aids to enhance the educational value of musculoskeletal DUS.

A secondary objective of the study was to evaluate the impact of prior DUS imaging on clinician and patient knowledge and attitudes. Although subgroup comparisons were not feasible due to the small sample sizes, a similar proportion of rheumatologists with DUS experience found the DUS imaging results useful, regardless of whether they performed the imaging themselves or referred patients externally (data not shown). In addition, most patients believed that discussing the DUS results helped them to better understand their disease and would help them adhere to their medications, regardless of whether their rheumatologist performed the imaging themselves or referred them to an external radiologist (data not shown). These observations suggested that DUS imaging need not be performed by the rheumatologist, as benefit was demonstrated even when the imaging was performed externally.

In summary, this study provides qualitative evidence that incorporating a single DUS assessment into routine consultation encourages rheumatologists to implement DUS imaging and positively impacts clinical practice. A prospective quantitative study is needed to confirm these findings. In addition, the findings suggest that DUS imaging is potentially a useful patient educational tool.

\section{REFERENCES}

1 Brown AK, Quinn MA, Karim Z, et al. (2006) Presence of significant synovitis in rheumatoid arthritis patients with disease-modifying antirheumatic drug-induced clinical remission: evidence from an imaging study may explain structural progression. Arthritis Rheum 54, 3761-3773.

2 Yoshimi R, Hama M, Takase K, et al. (2013) Ultrasonography is a potent tool for the prediction of progressive joint destruction during clinical remission of rheumatoid arthritis. Mod Rheumatol 23, 456-465.

This article is protected by copyright. All rights reserved 

and ultrasonographic remission determines different chances of relapse in early and long standing rheumatoid arthritis. Ann Rheum Dis 70, 172-175. Scire CA, Montecucco C, Codullo V, Epis O, Todoerti M, Caporali R. (2009) Ultrasonographic evaluation of joint involvement in early rheumatoid arthritis in clinical remission: power Doppler signal predicts short-term relapse. Rheumatology (Oxford) 48, 1092-1097.

5 Saleem B, Brown AK, Quinn M, et al. (2012) Can flare be predicted in DMARD treated RA patients in remission, and is it important? A cohort study. Ann Rheum Dis 71, 13161321.

6 Mclnnes IB, Schett G. (2011) The pathogenesis of rheumatoid arthritis. N EngI J Med $365,2205-2219$.

7 Brown AK, Conaghan PG, Karim Z, et al. (2008) An explanation for the apparent dissociation between clinical remission and continued structural deterioration in rheumatoid arthritis. Arthritis Rheum 58, 2958-2967.

Cohen G, Gossec L, Dougados M, et al. (2007) Radiological damage in patients with rheumatoid arthritis on sustained remission. Ann Rheum Dis 66, 358-363.

9 Molenaar ET, Voskuyl AE, Dinant HJ, Bezemer PD, Boers M, Dijkmans BA. (2004) Progression of radiologic damage in patients with rheumatoid arthritis in clinical remission. Arthritis Rheum 50, 36-42.

10 Mulherin D, Fitzgerald O, Bresnihan B. (1996) Clinical improvement and radiological deterioration in rheumatoid arthritis: evidence that the pathogenesis of synovial inflammation and articular erosion may differ. Br J Rheumatol 35, 1263-1268.

11 Saleem B, Brown AK, Keen $H$, et al. (2011) Should imaging be a component of rheumatoid arthritis remission criteria? A comparison between traditional and modified composite remission scores and imaging assessments. Ann Rheum Dis 70, 792-798.

12 Wakefield RJ, D'Agostino MA, Naredo E, et al. (2012) After treat-to-target: can a targeted ultrasound initiative improve RA outcomes? Ann Rheum Dis 71, 799-803.

This article is protected by copyright. All rights reserved 
13 Kane D, Balint PV, Sturrock R, Grassi W. (2004) Musculoskeletal ultrasound--a state of the art review in rheumatology. Part 1: Current controversies and issues in the development of musculoskeletal ultrasound in rheumatology. Rheumatology (Oxford) $43,823-828$.

14 Naredo E, D'Agostino MA, Conaghan PG, et al. (2010) Current state of musculoskeletal ultrasound training and implementation in Europe: results of a survey of experts and scientific societies. Rheumatology (Oxford) 49, 2438-2443.

15 Hama $M$, Takase $K$, Ihata $A$, et al. (2012) Challenges to expanding the clinical application of musculoskeletal ultrasonography (MSUS) among rheumatologists: from a second survey in Japan. Mod Rheumatol 22, 202-208.

16 Larche MJ, McDonald-Blumer H, Bruns A, et al. (2011) Utility and feasibility of musculoskeletal ultrasonography (MSK US) in rheumatology practice in Canada: needs assessment. Clin Rheumatol 30, 1277-1283.

17 Samuels J, Abramson SB, Kaeley GS. (2010) The use of musculoskeletal ultrasound by rheumatologists in the United States. Bull NYU Hosp Jt Dis 68, 292-298.

Troum OM, Pimienta OL, Schmidt WA, et al. (2015) Proceedings from the 7th Annual International Society for Musculoskeletal Imaging in Rheumatology (ISEMIR) conference. Semin Arthritis Rheum 45, 115-121.

19 Cannella AC, Kissin EY, Torralba KD, Higgs JB, Kaeley GS. (2014) Evolution of musculoskeletal ultrasound in the United States: implementation and practice in rheumatology. Arthritis Care Res (Hoboken) 66, 7-13.

20 Takase K, Ohno S, Ideguchi H, Takeno M, Shirai A, Ishigatsubo Y. (2010) Use of musculoskeletal ultrasound in Japan: a survey of practicing rheumatologists. Mod Rheumatol 20, 376-380.

21 Cunnington J, Platt P, Raftery G, Kane D. (2007) Attitudes of United Kingdom rheumatologists to musculoskeletal ultrasound practice and training. Ann Rheum Dis $66,1381-1383$.

22 Joplin SK, van der Zwan R, Bagga H, Joshua F, Wong PK. (2014) Pilot study assessing the novel use of musculoskeletal ultrasound in patients with rheumatoid arthritis to improve patient attitudes and adherence to medication. Int J Rheum Dis DOI: 10.1111/1756-185X.12402.

This article is protected by copyright. All rights reserved 
23 Joplin S, van der Zwan R, Joshua F, Wong PK. (2015) Medication Adherence in Patients with Rheumatoid Arthritis: The Effect of Patient Education, Health Literacy, and Musculoskeletal Ultrasound. Biomed Res Int 2015, 150658.

24 Joshua F. (2012) Ultrasound applications for the practicing rheumatologist. Best Pract Res Clin Rheumatol 26, 853-867.

25 van den Bemt BJ, Zwikker HE, van den Ende CH. (2012) Medication adherence in patients with rheumatoid arthritis: a critical appraisal of the existing literature. Expert Rev Clin Immunol 8, 337-351.

26 van den Bemt BJ, van Lankveld WG. (2007) How can we improve adherence to therapy by patients with rheumatoid arthritis? Nat Clin Pract Rheumatol 3, 681.

Table 1. Baseline characteristics of rheumatologists $(n=21)$

\begin{tabular}{ll}
\hline Characteristic & $\mathrm{n}(\%)$ \\
\hline Years since qualification as a rheumatologist & $10(47.6)$ \\
$<5$ years & $2(9.5)$ \\
$\quad$ 5-10 years & $9(42.9)$ \\
$>10$ years & $9(42.9) / 12(57.1)$ \\
\hline Single practice/group practice & $18(85.7) / 3(14.3)$ \\
\hline Public practice/private practice & $10(47.6)$ \\
\hline Access to specialist nursing support & \\
\hline Approximate number of RA patients treated per month & $11(52.4)$ \\
$<10$ & $4(19.0)$ \\
10-50 & $3(14.3)$ \\
\hline $50-100$ & \\
\hline
\end{tabular}

This article is protected by copyright. All rights reserved 


\begin{tabular}{ll}
\hline$>100$ & $2(9.5)$ \\
No response & $1(4.8)$ \\
\hline Number of rheumatologists who use validated assessment & \\
tools to & 17 (81.0) \\
Measure RA disease activity and response to therapy & $10(47.6)$ \\
Measure patient quality of life & \\
\hline $\begin{array}{l}\text { Current or previous utilization of DUS imaging for assessment } \\
\text { of RA activity }\end{array}$ & $8(38.1)$ \\
\hline Performed within the practice & $7(33.3)$ \\
\hline Patients referred to external radiologist & $6(28.6)$ \\
\hline
\end{tabular}

DUS, Doppler ultrasound; RA, rheumatoid arthritis.

Table 2. Characteristics of participating patients $(n=80)$

\begin{tabular}{ll}
\hline Characteristic & $n(\%)$ \\
\hline Age, years & $20(25.0)$ \\
& $24(30.0)$ \\
50 to $<60$ & $22(27.5)$ \\
270 & $14(17.5)$ \\
\hline Female & $66(82.5)$ \\
\hline Years since diagnosed with RA & \\
$\leq 2$ & $26(32.5)$ \\
\hline
\end{tabular}

This article is protected by copyright. All rights reserved 


\begin{tabular}{ll}
\hline$>2$ to $\leq 5$ & $7(8.8)$ \\
$>5$ to $\leq 10$ & $16(20.0)$ \\
$>10$ & $29(36.3)$ \\
Unknown & $2(2.5)$ \\
\hline Previous DUS imaging for assessment of RA & $19(23.8)$ \\
\hline
\end{tabular}

DUS, Doppler ultrasound; RA, rheumatoid arthritis.

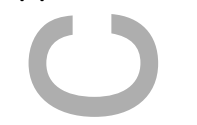

Table 3. Rheumatologist attitudes and utilization of DUS imaging at enrollment and 6 months post-activity, $\mathrm{n}(\%)$

\begin{tabular}{|c|c|c|}
\hline Questions & $\begin{array}{c}\text { Time of } \\
\text { enrollment } \\
(n=15)^{+}\end{array}$ & $\begin{array}{c}6 \text { months } \\
\text { post-activity, } \\
(n=21)^{\ddagger}\end{array}$ \\
\hline
\end{tabular}

Reasons rheumatologists had requested/would request DUS

imaging for assessment of an RA patient ${ }^{\S}$

Diagnostic tool to confirm inflammatory RA

Disease activity assessment to inform therapeutic decisions

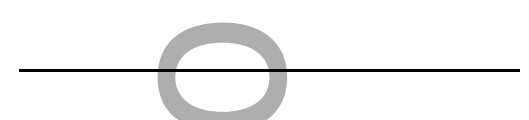

+ Data for time of enrollment was collected only from rheumatologists who had previous experience with the use of DUS imaging.

${ }^{\ddagger}$ Data for 6 months post-activity was collected from all rheumatologists.

$\S$ Responses at time of enrollment reflect rheumatologists' actual clinical practice ("had requested"), whereas responses 6 months post-activity reflect rheumatologists' attitudes ("would request") toward the use of DUS imaging. Rheumatologists could select more than 1 answer.

This article is protected by copyright. All rights reserved 


\begin{tabular}{|c|c|c|}
\hline Disease activity assessment to facilitate patient discussion & 0 & $14(66.7)$ \\
\hline Other & $1(6.7)$ & $3(14.3)$ \\
\hline \multicolumn{3}{|l|}{$\begin{array}{l}\text { Rheumatologists who had requested/would request DUS imaging } \\
\text { to measure disease activity in RA patients with }\end{array}$} \\
\hline Disease remission & $4(26.7)$ & $12(57.1)$ \\
\hline Low disease activity & $10(66.7)$ & $18(85.7)$ \\
\hline Moderate disease activity & $2(13.3)$ & $5(23.8)$ \\
\hline Severe disease activity & 0 & $6(28.6)$ \\
\hline Other patients & 0 & $2(9.5)$ \\
\hline \multicolumn{3}{|l|}{ Rheumatologists who believed in utilizing DUS to assess RA } \\
\hline \multicolumn{3}{|l|}{ patients aids } \\
\hline Therapeutic decision-making & $13(86.7)$ & $19(90.5)$ \\
\hline Communication with your patient & $12(80.0)$ & $17(81.0)$ \\
\hline Patient adherence and compliance with therapy & $9(60.0)$ & - \\
\hline
\end{tabular}

DUS, Doppler ultrasound; RA, rheumatoid arthritis

\section{FIGURE LEGEND}

Figure 1. Example of the patient visual aids.

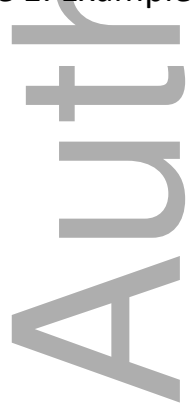

This article is protected by copyright. All rights reserved 

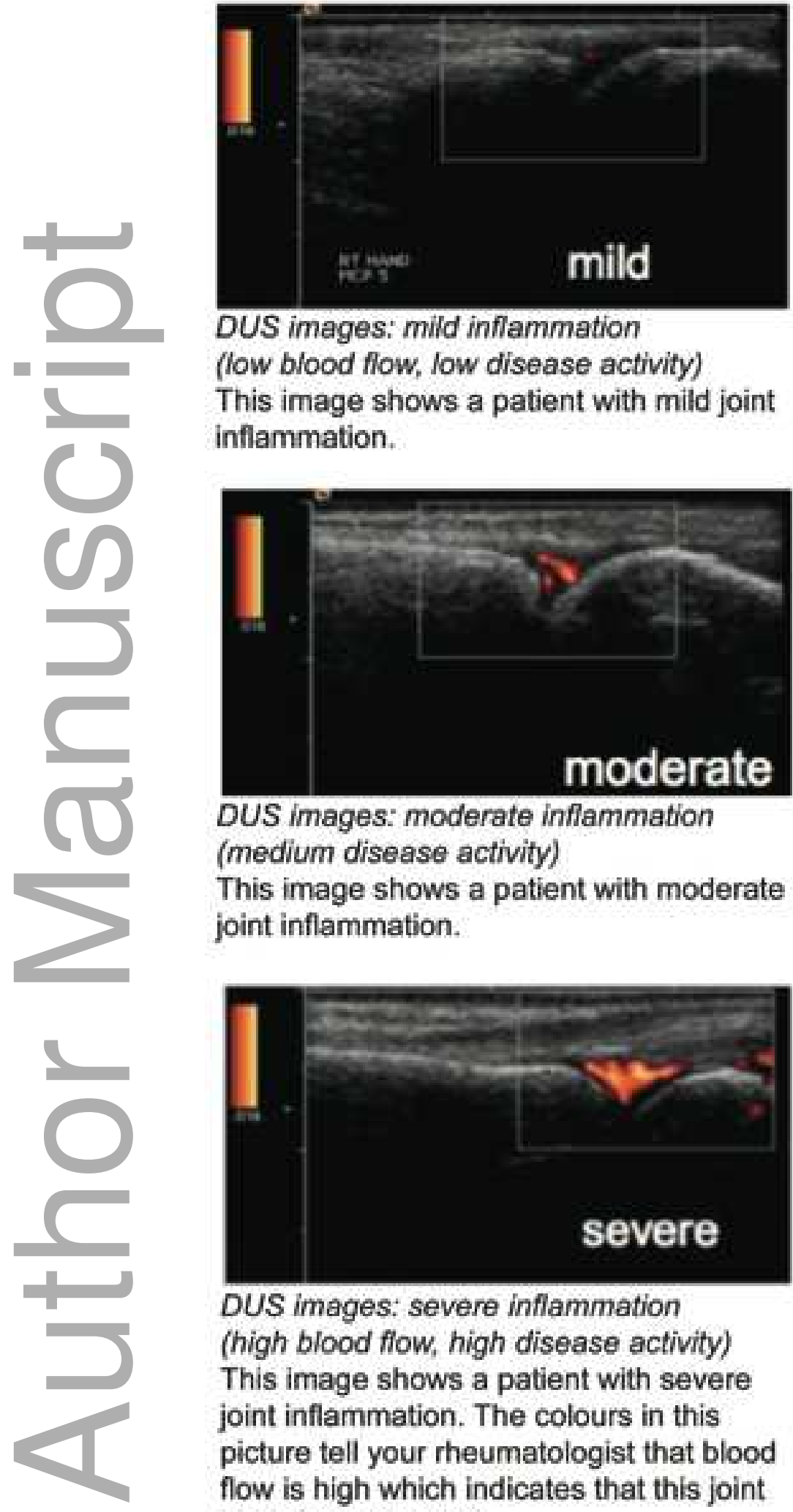

DUS images: mild inflammation (low blood flow, low disease activity)

This image shows a patient with mild joint inflammation.

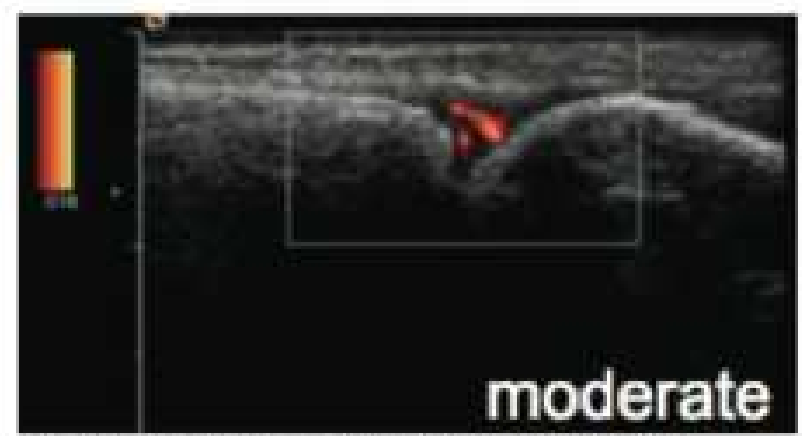

DUS images: moderate inflammation (medium disease activity)

This image shows a patient with moderate joint inflammation.

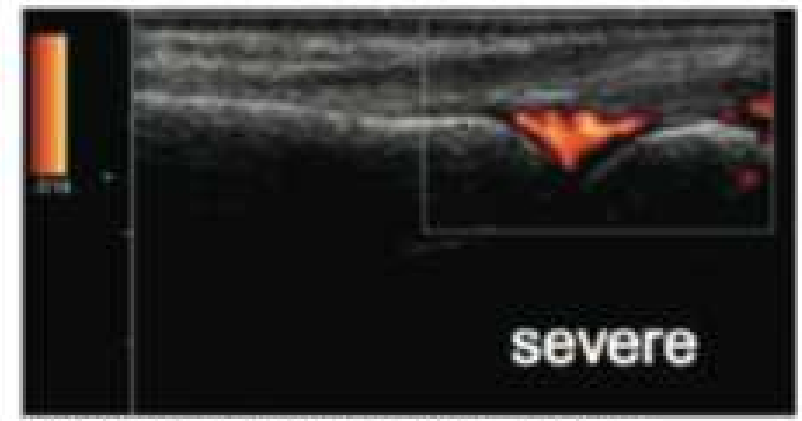

DUS images: severe inflammation (high blood flow, high disease activity) This image shows a patient with severe joint inflammation. The colours in this picture tell your rheumatologist that blood flow is high which indicates that this joint is severely inflamed.

apl_13034_f1.tiff 


\section{University Library}

\section{- M M N E R VA A gateway to Melbourne's research publications}

Minerva Access is the Institutional Repository of The University of Melbourne

Author/s:

Joshua, F;Bailey, C;Marabani, M;Romas, E;White, R;Wong, P

Title:

Perceptions of Doppler ultrasound for rheumatoid arthritis disease activity assessment and education

Date:

2019-01-01

Citation:

Joshua, F., Bailey, C., Marabani, M., Romas, E., White, R. \& Wong, P. (2019). Perceptions of Doppler ultrasound for rheumatoid arthritis disease activity assessment and education. INTERNATIONAL JOURNAL OF RHEUMATIC DISEASES, 22 (1), pp.55-61. https:// doi.org/10.1111/1756-185X.13034.

Persistent Link:

http://hdl.handle.net/11343/292449 